\title{
Increased Incidence of Deep Vein Thrombosis after Myocardial Infarction in Non-smokers
}

\author{
PETER MARKS， PETER A. EMERSON
}

TABLE I-Incidence of Deep Vein Thrombosis in Smokers and Non-smokers

\begin{tabular}{r|c|c|c}
\hline & Non-smokers & Smokers & Total \\
\hline $\begin{aligned} \text { Deep vein thrombosis } \\
\text { No deep vein thrombosis }\end{aligned}$ & $23(62 \%)$ & $7(11 \%)$ & $30(29 \%)$ \\
\hline Total & 37 & 58 & 72 \\
\hline
\end{tabular}

$x^{2}=30.0 ; P<0.00001$. coronary care unit at this hospital and not treated with anticoagulants $30(29 \%)$ developed isotopic evidence of deep vein thrombosis. Of the 65 smokers only $7(11 \%)$ developed a deep vein thrombosis, whereas of the 37 non-smokers 23 $(62 \%)$ developed a deep vein thrombosis. This difference is highly significant $(P<0.00001)$.

\section{Introduction}

In the preceding study (Handley and Teather, 1974), which was designed to identify patients especially likely to develop a deep venous thrombosis, a surprising finding was that patients with myocardial infarction who had smoked cigarettes up to the time of admission to the coronary care unit at Queen Mary's Hospital, Roehampton, appeared less likely to develop a deep vein thrombosis than patients in the same unit who had not smoked. The present report is on the results of an independent study made in the coronary care unit at Westminster Hospital.

\section{Patients and Methods}

All patients entering the coronary care unit over a period of 10 months with a clinical diagnosis of myocardial infarction which fulfilled the W.H.O. criteria were included in the study; there were 102 such patients. Each patient was given an intravenous injection of ${ }^{125}$ I-fibrinogen on admission and their legs were scanned each day using the techniques described by Kakkar et al. (1970). The scanning was continued until the 14th day in all except six of the patients, who had died before the 14th day; they were, however, included in the analyses. A persistent difference in uptake of more than $15 \%$ between corresponding portions of the legs or between adjacent points on the same leg was taken to indicate the presence of a venous thrombosis.

The average daily number of cigarettes, cigars, or pipes smoked before admission was recorded. It had been our intention to classify anyone who had given up smoking more than 30 days before admission as a non-smoker, but in the event none had done so.

\section{Results}

The incidence of deep vein thrombosis for the whole series was $29 \%$ (30 patients); for the 65 smokers it was $11 \%$ (7 patients), and for the 37 non-smokers it was $62 \%$ (23 patients). The increased incidence in non-smokers was highly significant $(\mathrm{P}<0.00001)$ (table $\mathrm{I})$.

\footnotetext{
Westminster Hospital, London SW1P 2AP

PETER MARKS, M.B., M.R.C.P., Senior House Officer to Coronary Care Unit (Present address: Royal Postgraduate Hospital, London W12)

PETER A. EMERSON, M.D., F.R.C.P., Consultant Physician
}

In view of this finding the series was re-examined to see whether the explanation might be an unequal distribution between the "smoker" and "non-smoker" groups of patients with an otherwise high risk of deep vein thrombosis after myocardial infarction. The three high-risk groups that we were able to identify are shown in tables II, III, and IV.

There was no significant difference in the incidence of deep vein thrombosis between patients below 50 years of age and those aged 50 to 69 years, but the incidence was significantly higher in patients aged 70 years and over as compared with all those below that age $(P=0.051)$ (table II). There was also a significantly higher incidence of deep vein thrombosis among patients who had either varicose veins $(P<0.00001)$ or a previous history of deep vein thrombosis $(P<0.002)$ (tables III and IV).

TABLE II-Incidence of Deep Vein Thrombosis according to Age

\begin{tabular}{r|c|c|c|c}
\hline Age (years): & $<50$ & $50-69$ & $>70$ & Total \\
\hline $\begin{array}{r}\text { Deep vein thrombosis } \\
\text { No deep vein thrombosis }\end{array}$ & $5(28 \%)$ & $19(26 \%)$ & $6(55 \%)$ & $30(29 \%)$ \\
\hline Total & 18 & 73 & 11 & 102 \\
\hline
\end{tabular}

Significance of difference between age groups $<50$ and 50-69: $x^{2}=0.02 ; P<0.90$ (N.S.).

Significance of difference between age groups above and below 70: $\chi^{2}=0.02$; $\mathbf{P}=0.051$.

TABLE III-Relation between Deep Vein Thrombosis and Presence of Varicose Veins

\begin{tabular}{ll|c|c}
\hline & No Varicose Veins & Varicose Veins \\
\hline $\begin{array}{ll}\text { Deep vein thrombosis } \\
\text { No deep vein thrombosis }\end{array}$ & $21(23 \%)$ & $9(82 \%)$ \\
\hline & Total & 91 & 2 \\
\hline
\end{tabular}

$\chi^{2}=16.3 ; P<0.0001$.

TABL.8 IV-Relation between Presence of Deep Vein Thrombosis and Past

\begin{tabular}{ll|l|l}
\hline & & Absence & Presence \\
\hline $\begin{array}{l}\text { Deep vein thrombosis } \\
\text { No deep vein thrombosis }\end{array}$ & $26(27 \%)$ & $4(100 \%)$ \\
\hline & Total & 98 & 0 \\
\hline
\end{tabular}

$\chi^{2}=10.0 ; P<0.002$.

To eliminate any bias due to an unequal distribution of patients in any of these three higher risk groups all patients over 70 years old and those with clinically significant variHistory of Deep Vein Thrombosis 
cose veins or a history of deep vein thrombosis were excluded (table $\mathrm{V}$ ). The incidence of deep vein thrombosis became $52 \%(13 / 25)$ in the non-smokers and only $5.4 \%(3 / 56)$ in the smokers. This difference is again highly significant $(\mathrm{P}<0.00001)$.

TABLE v-Incidence of Deep Vein Thrombosis in Smokers and Non-smokers after Removal of High-risk Patients (Those with Varicose Veins, History of Previous Venous Thrombosis, or Age over 70)

\begin{tabular}{|c|c|c|}
\hline & Smokers & Non-smokers \\
\hline $\begin{array}{l}\text { Deep vein thrombosis } \\
\text { No deep vein thrombosis }\end{array}$ & $53^{3(5 \cdot 4 \%)}$ & $\begin{array}{l}13(52 \%) \\
12\end{array}$ \\
\hline Total & 56 & 25 \\
\hline
\end{tabular}

$\chi^{2}=23.7 ; P<0.00001$.

There was no significant difference in the incidence of deep vein thrombosis between those who smoked a pipe and those who smoked cigarettes (none smoked both) (table VI). Furthermore there was no positive correlation between the numbers of cigarettes smoked and the incidence of deep venous thrombosis.

TABLE VI-Relation between Type of Smoker and Quantity Smoked and Incidence of Deep Vein Thrombosis

\begin{tabular}{l|c|c|c}
\hline & $\begin{array}{c}\text { Pipe } \\
\text { or } \\
\text { Cigar }\end{array}$ & $\begin{array}{c}1-10 \\
\text { Cigarettes } \\
\text { Daily }\end{array}$ & $\begin{array}{c}\text { Cigates } \\
\text { Daily }\end{array}$ \\
\hline $\begin{array}{l}\text { Deep vein thrombosis } \\
\text { No deep vein thrombosis }\end{array}$ & $2 \cdot(22 \%)$ & $\begin{array}{c}4(13 \%) \\
27\end{array}$ & $\begin{array}{l}1(4 \%) \\
24\end{array}$ \\
\hline
\end{tabular}

$\chi^{2}=2.5 ; P<0.30$ (N.S.). There was no significant difference in incidence of deep vein thrombosis among the
three groups of smokers.

\section{Discussion}

The overall frequency of venous thrombosis after myocardial infarction in this series was similar to that reported by other workers, but in our patients the non-smokers were much more likely to develop deep vein thrombosis after their myocardial infarctions than were the smokers. This is surprising because smoking is generally believed to increase the risk of venous thrombosis.

On admission to the coronary care unit all smokers have to stop smoking, but it seems unlikely that any rebound hypocoagulability state could actually protect smokers from deep vein thrombosis so that they suffer from this less than non-smokers.

We considered whether these results could have been due to bias on the part of the observer making the scans, but, for the first 78 patients, these had been completed before there was any suspicion of the importance of the smoking habits. For the next 24 patients the relation was suspected but it seems unlikely that this knowledge could have materially affected the recording of the results.

Another possibility that was considered was that there might be a relationship between build-that is, weight in relation to height-which might itself be related to smoking, and the incidence of deep vein thrombosis. The distribution of the smokers and non-smokers according to build is shown in fig. 1. The values for the percentage of weight for height above and below normal are taken from the build tables of the $\mathbf{M}$ and $\mathbf{G}$ insurance manual. The non-smokers were not heavier for height than the smokers, so that there were no significant differences in build between the two groups to explain the increased incidence of deep vein thrombosis in the non-smokers; there was not, in any case, any relation between build and the incidence of deep vein thrombosis in our patients.

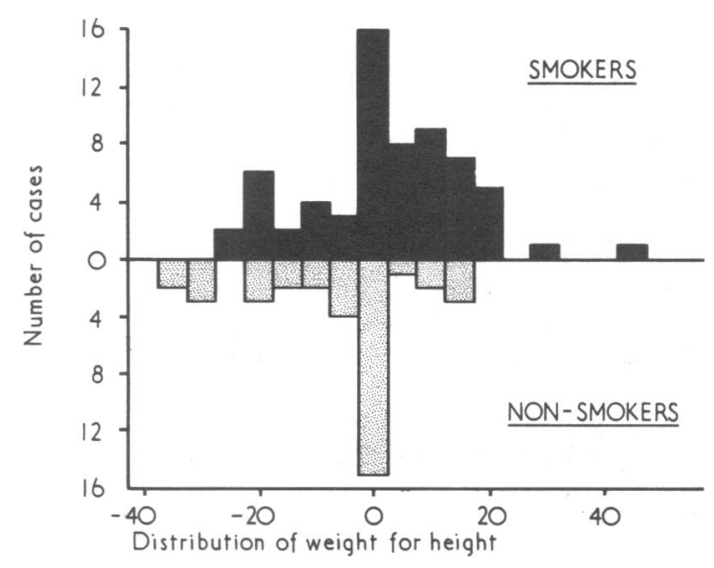

FIG. 1-Distribution of smokers and non-smokers according to build, expressed as percentage deviation above and below expected normal weight for height.

One possible and rather simple explanation for the decreased incidence of deep vein thrombosis in smokers might be that they are more fidgety than non-smokers, so that they move about in bed more, especially if they have been deprived of their cigarettes. Whether or not smokers do move about more in bed could readily be studied.

The observation (table VI) that there was no significant difference in the incidence of deep vein thrombosis between those who smoked a pipe or cigars and those who smoked either more or fewer than 10 cigarettes a day suggests that the effect is not related to the previous cigarette consumption but is in some way related to the inherent constitution of the smoker.

An interesting explanation in our view is that patients who enter the coronary care unit may be drawn mainly from two groups of people. There may be one group of patients with a tendency to thrombosis ("clotters"), some of whom smoke, and another group without this tendency but who all smoke. These two hypothetical populations are represented by the two overlapping circles in fig. 2.

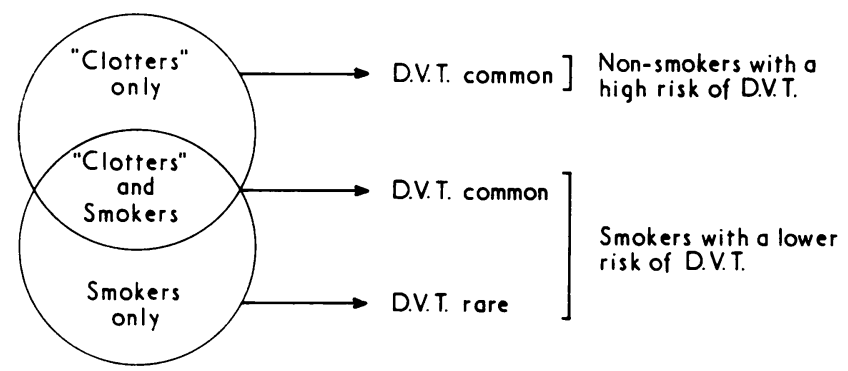

FIG. 2-Two hypothetical overlapping populations of "clotters" and smokers and resulting different incidences of deep vein thrombosis (D.V.T.) in and resulting different in

The "clotters" may develop their cardiac infarction because they readily develop thrombosis and therefore also have a high incidence of venous thrombosis. The smokers may develop their cardiac infarction because they smoke, so that those who are not also "clotters" will not readily develop a deep vein thrombosis. It may be only those smokers 
who are also "clotters" who develop deep vein thrombosis, and this may explain the lower incidence of deep vein thrombosis in the smokers as a whole.

None of these theories is really satisfactory but whatever the true explanation the observations are important when it comes to making decisions about which patients should be given anticoagulant therapy to prevent thromboembolic complications after myocardial infarction. Non-smokers join those with clinically significant varicose veins and those with a history of previous thromboembolism in the high-risk group, in whom prophylactic anticoagulant therapy is indicated (Emerson, 1974; Emerson et al., 1974).

\section{References}

Emerson, P. A. (1974). Bulletin of the Institute of Mathematics and its Applications, 10, 33.

Emerson, P. A., Teather, D., and Handley, A. (1974). Quarterly Fournal of Medicine. In press.

Handley, A. J., and Teather, D. (1974). British Medical fournal, 3, 230.

Hakkar, V. V., et al. (1970). Lancet, 1, 540.

\section{MEDICAL MEMORANDA}

\section{Lichenoid Eruption due to Methyldopa}

\section{P. J. A. HOLT, A. NAVARATNAM}

British Medical fournal, 1974, 3, 234

Many drugs can produce an eruption that may be histologically and clinically indistinguishable from or closely similar to lichen planus. Lichenoid eruptions occurring in patients receiving methyldopa appear to be rare. The following such case illustrates a causal relation between the drug and the eruption. The diagnostic impontance of establishing this relationship is emphasized.

\section{Case Report}

A 60-year-old housewife was found to be hypertensive in June 1971. Methyldopa $250 \mathrm{mg}$ three times daily was begun and she became normotensive. In September 1972 she noticed a symmetrical rash on the forearms which spread to the trunk and legs. Itching was not severe. Treatment was continued.

When seen in June 1973 she had a symmetrical lichenoid eruption on the legs, trunk, and arms. The mucous membranes, scalp, and nails were spared. Biopsy showed hyperkeratosis, hypergranulosis, irregular acanthosis with flattening of the rete ridges, and a predominantly eosinophilic infiltrate in the upper dermis (see fig.). Methyldopa was stopped and her blood pressure was controlled with oxprenolol $80 \mathrm{mg}$ twice daily. Fourteen days later the eruption was beginning to fade and by September it had cleared. In October methyldopa was restarted at a dose of $250 \mathrm{mg}$ twice

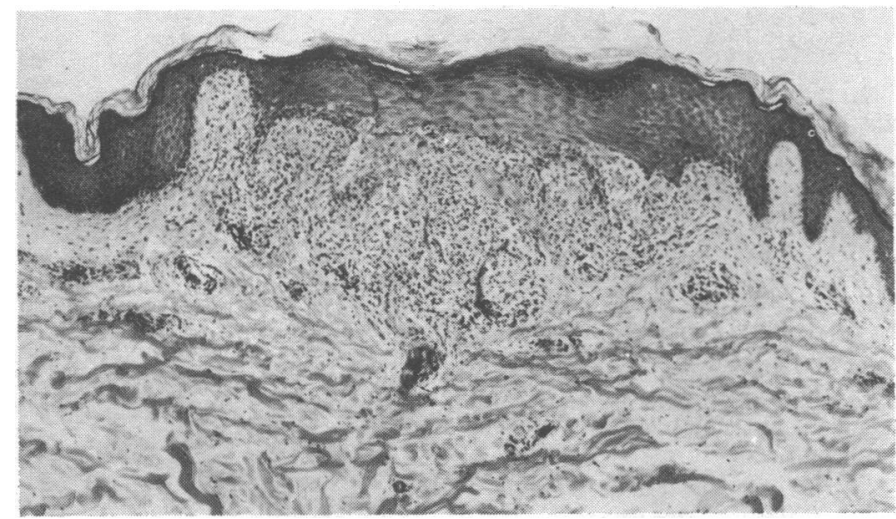

Appearances of skin biopsy specimen from trunk. (H. and E. $\times$ 39.)

Department of Dermatology, University Hospital of Wales, Cardif CF4 4XN

P. J. A. HOLT, M.B., M.R.C.P., Registrar

A. NAVARATNAM, M.B., M.R.C.P., Senior Registrar daily. Seventeen days later a lichenoid eruption developed on the back and shoulders. Biopsy showed changes of lichen planus. Methyldopa was replaced by oxprenolol and seven days later the eruption disappeared.

\section{Comment}

Methyldopa is the alpha-methylated derivative of dihydroxyphenylalanine. Skin reactions in patients receiving methyldopa are not common. Dollery (1965) described three patients who developed a pruritic papular eruption on the legs, and Peterkin and Khan (1969) described four patients with a keratotic eczema on the palms and soles. Church (1973) reported on 13 patients with a seborrhoeic, dermatitis-like eruption which developed while taking methyldopa. There have been other instances of eruptions attributable to methyldopa (Almeyda and Levantine, 1973).

Stevenson (1971) reported the development of a lichenoid eruption in three patients on methyldopa after 18 months, five months, and six months of treatment respectively. The eruption subsided after discontinuing treatment but no provocation tests were performed on any of his patients. In our patient the lichenoid eruption first developed 15 months after starting methyldopa and reappeared only 17 days after restarting the drug. The histological pioture showed an eosinophilic pervascular infiltrate. These features suggest a causal relation between the drug and the eruption.

The clinical appearance of a lichenoid drug eruption may be indistinguishable from that of lichen planus. Occasionally there are atypical features such as pronounced scaling, eczematization and intense residual pigmentation (Samman, 1972). The histological pioture is generally identical with that of lichen planus, though Winer and Leeb (1954) believe that there are differences in lichenoid drug eruptions, having observed in panticular the presence of a prominent eosinophilic perivascular infiltrate in the dermis, a feature not seen in lichen planus. In view of the possible identical clinical and histological features of the two conditions it is necessary to establish a causal relation between the drug an dithe lichenoid eruption in onder to exclude the diagnosis of coincidental lichen planus.

We should like to express our thanks to Dr. E. Waddington and Dr. H. J. Whiteley for their help with this report.

\section{References}

Almeyda, J., and Levantine, A. (1973). British fournal of Dermatology, 88, 313.

Church, R. E. (1973). British fournal of Dermatology, 89, Suppl. No. 9, p. 10 Dollery, C. T. (1965). Progress in Cardiovascular Diseases, 8, 278.

Peterk, G A G and Khan, S. A. (1969). Practitioner, 202, 117.

Peterkato P. D. (1972) In Textbook of Dermatology, Rook, D. S Wilkinson, and J. F. G. Ebling, vol. 2, p. 1350 . Oxford, Blackwel Scientific.

Stevenson, C. J. (1971). British fournal of Dermatology, 85, 600.

Stevenson, C. J. (1971). British Fournal of Dermatology, 85, 600 .
Winer, L. D., and Leeb, A. J. (1954). Archives of Dermatology and Syphilology, 70, 274. 